\title{
The Developmental Stages of Rice (Bap) Culture in Korea: From Food Insufficiency towards Trade Dependency
}

\author{
Kim Bok-rae \\ The Department of European Culture and Tourism, Andong National University, Andongsi 36729, South Korea
}

\begin{abstract}
The aim of this paper is to examine the developmental stages of rice culture in Korea. It is divided into five sections: (1) first stage (Japanese colonial period-1959): absolute food insufficiency, (2) second stage (1960s): encouraging the use of flour \& rice with mixed grains for food, (3) third stage (1970s): rice self-sufficiency, (4) fourth stage (1980s): change of rice culture, (5) fifth stage (since1990s): stabilization/stagnation of rice culture in the era of globalization.
\end{abstract}

Key words: Rice culture, food insufficiency, rice self-sufficiency, industrialization of rice, globalization.

\section{Introduction: Rice as Korean Soul Food}

Among three East Asian Countries (China, Korea and Japan), rice may be of the greatest importance in Korean culinary culture. During the Chosun dynasty (1392-1910), Korean per capita consumption of rice was higher than Chinese/Japanese ones. For reference, Hong Dae-yong (1731-1783) ${ }^{1}$ wrote that a rice bowl was about of the size of a teacup in Ming dynasty after his return from China. A Korean envoy to Japan was also surprised to see people eat a handful of rice in Nippon. According to the Collection of Essays of Yongjae in 1525, "Poor people eat their fill even going to the extent of incurring debt. Soldiers carry provisions which occupy almost half of their whole luggage in the march. Government officials often get together to have drinks." According to the Diary of Soemirok (1591-1601), "Chosun (old Korean) adult

Corresponding author: Kim Bok-rae, Ph.D. in economic history at the University of Paris I (France), professor, research fields in comparative research Europe vs. East Asia.

*This work was supported by a grant from 2015 Research Funds of Andong National University.

${ }^{1}$ Hong Dae-yong (1731-1783) was a philosopher, astronomer and mathematician of the late Chosun Kingdom. Hong was an early leader of the "Profitable Usage and Benefiting" school of thought. It worked to promote the industrialization of his country and the development of trade by positively introducing Western technologies to Korea. males eat more than 7-hop $(1,260 \mathrm{~mL})$ rice at a meal." 2 For that reason, Westerners who visited Korea at the end of the Chosun dynasty, including a French missionary and saint Marie-Nicolas-Antoine Daveluy (1818-1866), called Chosun by her nickname "gluttonous nation." [1] William Elliot Griffs (1843-1928) in his Corea, the Hermit Nation in 1882, wrote that Koreans are openly boasting about overeating, regardless of the levels of inequality between rich and poor [2].

Korean daily meal consists of rice (bap) and side dishes (banchan), but the former is considered as more precious than the latter in Korean dietary culture. Koreans use "both spoon and chopsticks": one for eating rice and soup ( $g u k)$, and the other for picking up side dishes, unlike their Chinese and Japanese counterparts who use only chopsticks (to eat rice) at table (Fig. 1). For Koreans spoon and chopsticks are one; that is, two-in-one system. Yoon Dae-nyeong, a South Korean writer, in his Essay Collection Mother's Spoon and Chopsticks in 2006, compared a set of spoon and chopsticks with holder (Fig. 2) to a happily married couple resting their head on a pillow. Spoon is the most important tool on the Korean dining table,

\footnotetext{
21 hop $=180 \mathrm{~mL}$.
} 
to such an extent as to saying colloquial term: "put down one's spoon" when a person died. In his novel One Spoon on the Earth in 1999, Hyun Ki-young wrote "spoon is rice (bap), and rice is life". [3] The reason why spoon was so indispensable to Koreans and their traditional foods was and is, mainly due to the development of Korean soup-like dishes ( $g u k$ and tang) (Fig. 3) and their peculiar habits of eating "too much and too fast," and/or liking warm and hot foods. For reference, Chinese eat fried rice (chaofan) (Fig. 4), Japanese eat rice with toppings (donburi) (Fig. 5), and Koreans eat rice with mixed vegetables (bibimbap) (Fig. 6) which is closely related to Korean spoon-using culture: namely, the most efficient way to eat rice.

In old days, one of the greatest wishes of Koreans was to eat "white rice and beef soup", but they could not feast on them, except under special circumstances (for ancestral rites, holidays and entertaining guests). Rice was so precious, as to be often used as a cash in special cases. Thus, white rice was the indicator of wealth in pre-modern society. It is only a short time that Koreans could eat rice every day. In 1960s when there was not enough rice and even till 1970s, the then Korean government did not only encourage people to eat more flour based food and mixed grains, but also let them sing a pro-flour (or multi-grain) song, as a mass-education campaign. Nowadays, however, Korean per capita rice consumption has been markedly decreasing. The volume of a rice bowl is $290 \mathrm{~mL}$. Even, one-half bowl entered the market, especially for female consumers who want to lose weight.

In accordance with rapid economic growth and industrialization called "the miracle of Han river," newly appeared phenomena such as socio-economic value shifts, food gentrification and diversification, fast-foodization and restaurant industry, etc. With the increase in income, Koreans today tend to eat more meat and/or to show food overconsumption. Thanks to "white revolution of agriculture" in Korea and import opening, people can eat all kinds of fruits and vegetables all year around. Therefore, rice consumption has been falling or slowing down, especially with young generation's pro-west eating habits (Table 1). Furthermore, due to the westernization of Korean dietary practices, the number of obese people with adult diseases has increased. From the past low-nutrition into the present high-nutrition periods, malnutrition and hyper-nutrition coexists today in Korea. So, it's necessary to maintain a reasonable nutritional balance, through a rice-based balanced diet.

The aim of this paper is to examine the developmental stages of rice culture in Korea. It is divided into five sections: (1) first stage (Japanese

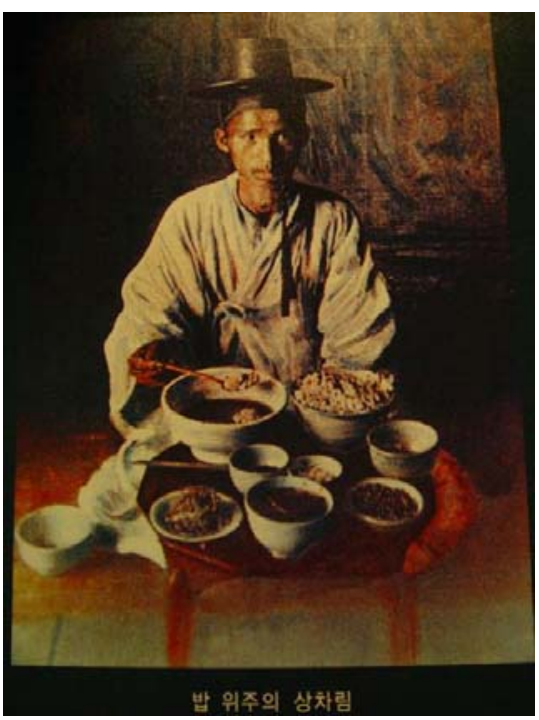

Fig. 1 Rice-based table-setting.

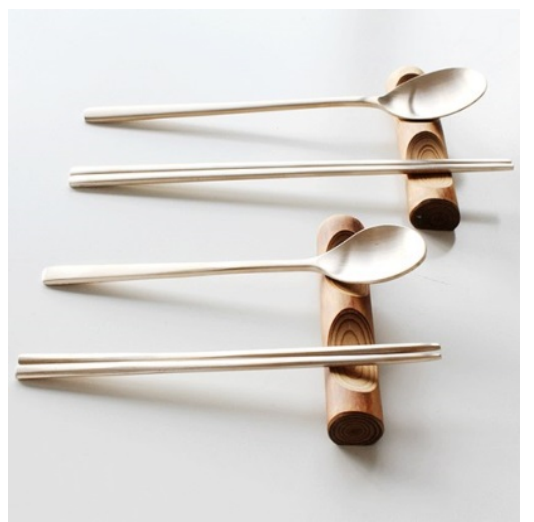

Fig. 2 Two sets of spoon \& chopsticks with holder. 

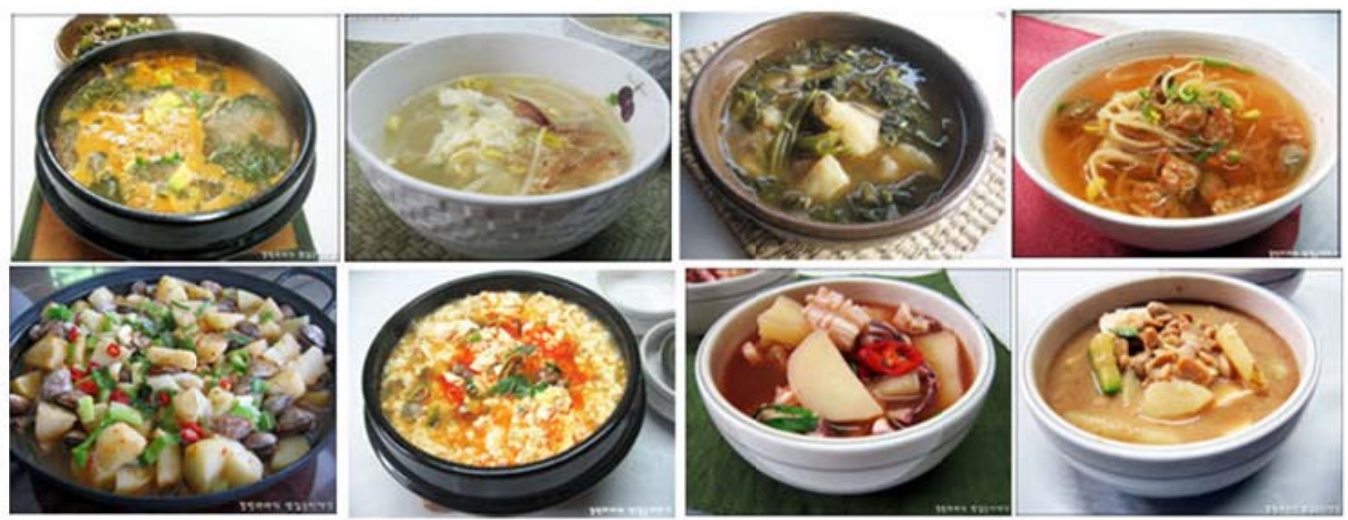

Fig. 3 Korean soup-like dishes (guk and tang).

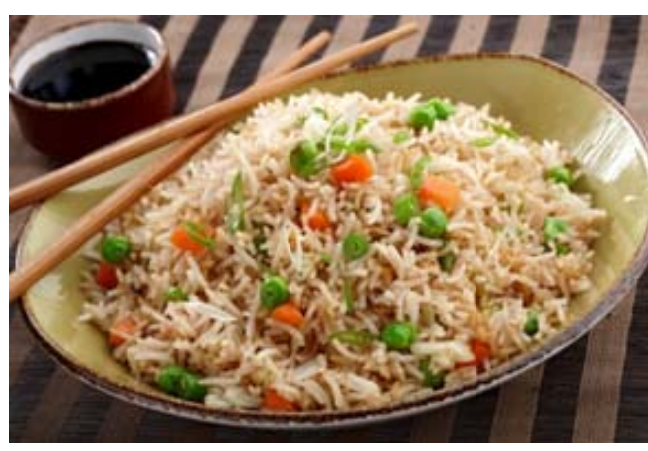

Fig. 4 Chinese fried rice (chao fan).

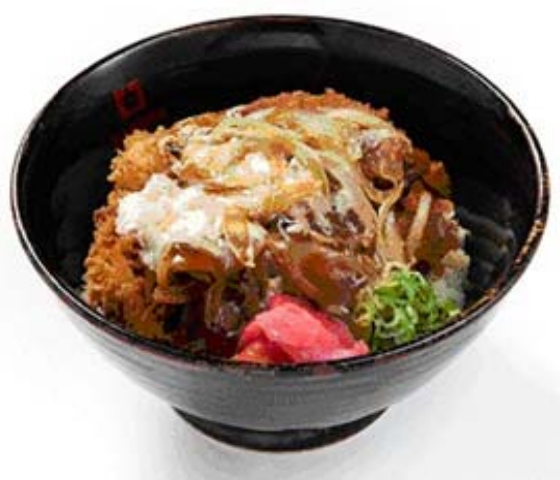

Fig. 5 Japanese rice with topping (donburi).

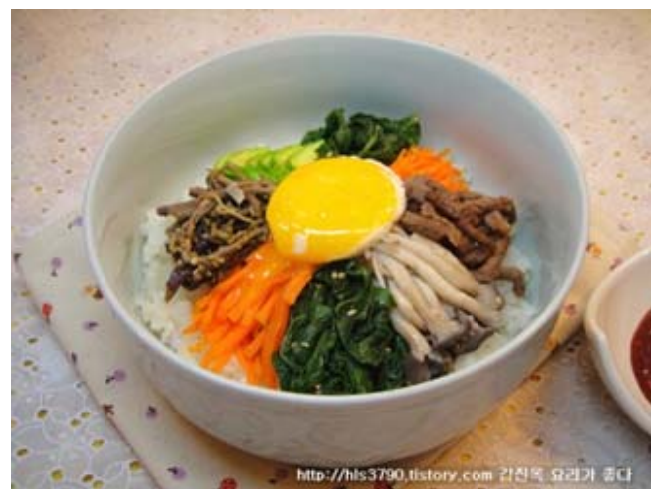

Fig. 6 Korean rice with mixed vegetables (bibimbap).

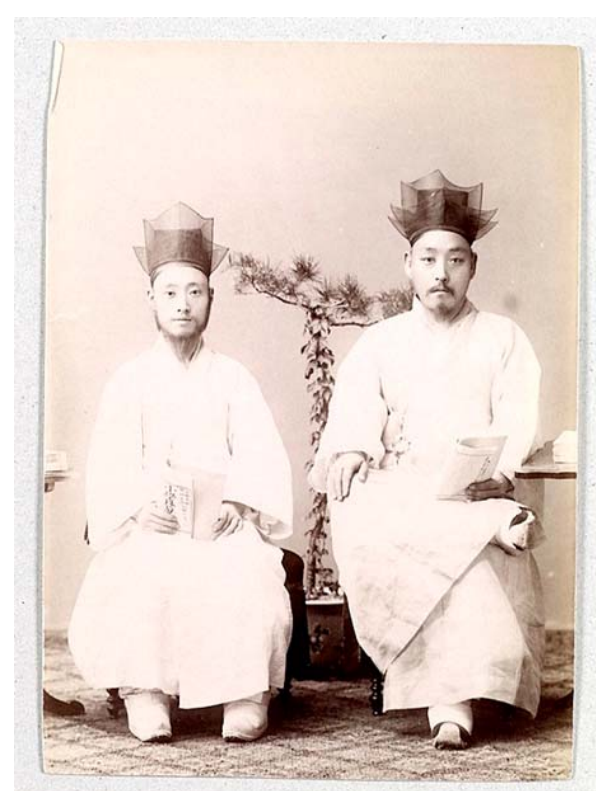

Fig. 7 Korean aristocrats “yangban”.

colonial period-1959): absolute food insufficiency, (2) second stage (1960s): encouraging the use of flour \& rice with mixed grains for food, (3) third stage (1970s): rice self-sufficiency, (4) fourth stage (1980s): change of rice culture, (5) fifth stage (since1990s): stabilization/stagnation of rice culture in the era of globalization.

\section{The First Stage (Japanese Colonial Period-1959): Absolute Food Insufficiency}

Koreans experienced "food insecurity" in this first stage, especially during the 1950-1953 Korean War where they were forced to live at the subsistence level. As R. H. Tawney compared the conditions of Chinese 
Table 1 Size variation of a rice bowl by year.

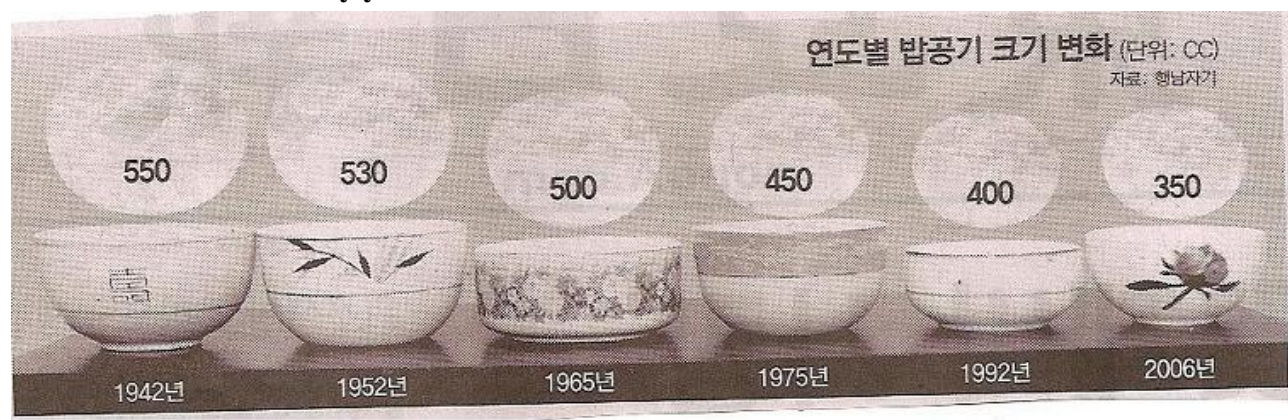

\begin{tabular}{lllllll}
\hline Year & 1942 & 1952 & 1965 & 1975 & 1992 & 2006 \\
\hline Volume $(\mathrm{mL})$ & 550 & 530 & 500 & 450 & 400 & 350 \\
\hline
\end{tabular}

farmers in 1930s to "that of a man standing permanently up to the neck in water, so that even a ripple is sufficient to drawn him," [4] Korean farmers had faced serious crises in growing rice for hundreds of years. During the Chosun dynasty (1397-1910), Korean farmers had to do rice farming for a small ruling class (state, royal family, and yangban aristocrats $)^{3}$ who reigned over them by monopolizing land (Fig. 7). Rice was a symbol of wealth to landlords, but that of exploitation to (tenant) farmers and wage laborers.

Rice Koreans eat today is derived from improved rice varieties Japan developed after Meiji Restoration. During Japanese colonial period (1910-1945), Korean farmers experienced new farming technologies. High-yielding Japanese rice species were introduced into Chosun (old Korea), in place of low-yielding native rice species, which had been used for a long time in Korean peninsula. Many Korean small framers who had solely depended on rainfall for water till then, started to farm in irrigated paddies, applying high-yielding varieties and artificial fertilizers ${ }^{4}$. As a

\footnotetext{
${ }^{3}$ The yangban were part of the traditional ruling class or gentry of dynastic Korea during the Chosun dynasty. The yangban were mainly composed of civil servants and military officers. The yangban were landed or unlanded aristocracy who comprised the Korean Confucian idea of a "scholarly official." ${ }^{4}$ High-yielding varieties, artificial fertilizers, and irrigation farming were first developed in Japan in the transition from old empiricism-based farming skills into new mechanism-based \&western farming technologies. After colonizing Korea, Japan fostered their improved farming techniques over Korea for the efficient colonial agricultural development.
}

result, Korean land productivity increased from 0.8 rice bag ( 1 rice bag $=180$ liters) into 1.4 per danbo (old area unit) in the mid-1930s. In spite of rapid labor-intensive agricultural growth, the "polarization of wealth" in rural areas became more serious ${ }^{5}$ [5].

Since around the 1890 s, Japan imported rice from Korea. Korean rice was less tasty, but its price was $10 \%$ cheaper than Japanese one [6]. Japan was not self-sufficient in rice, thus Japanese traders could make a profit from purchasing cheap rice from Korea. Looking back on it, this Japanese colonial trade pattern with Korea is very similar to the actual Korean trade pattern with China where Korea inversely imports cheap rice from China. As Japanese capitalism developed, the domestic food problem became more acute in the mainland; therefore, the Japanese demand for Korean rice was growing. In 1920s, Japanese government started to enforce a rice regulation policy in the Japanese Archipelago. During the late period of Taisho (1912-1926) ${ }^{6}$ the imperial government pushed forward industrialization by using rice, on the basis of the motto "national prosperity and military power." For example, many enticing (semi-) governmental "job ads" offering "three meals of rice a day" appeared during that time to pull rural women

\footnotetext{
5 The input of commercial fertilizer-causing a heavy money spending - was the greatest burden especially to poor farming families..

6 The Taisho period is a period in the history of Japan dating from July 30, 1912, to December 25, 1926, coinciding with the reign of the Emperor Taisho.
} 
into factory labor forces. They showed signs of "rice shortages" in Japanese rural society. In the conflicts and confrontations between government and civilians, rice was not widely popularized among the masses, but degenerated into political means to retain or extend the power of ruling class [7]. In the 1920s, Japan established the 15-year rice production increase plan of Korea to yield 9,200,000 rice bags. This plan was not brought into realization, but Korea became a Japanese strategic base for securing food [8]. Even though Korean rice production plan was not achieved as planned, there was a considerable increase in the export of rice to Japan (more than the amount of increased Korean rice production) (Fig. 8). This meant rice consumption remarkably decreased in Korea.

Rice was not only a meal, but the "moral" politics (or barometer) to measure public welfare stability. In Japanese colonial period, it became an object of "han" in Korean (lament and injustice). ${ }^{7}$ Most Koreans had to fill their stomach with mixed grains imported from Manchuria, except pro-Japanese landlords, while others barely managed to stay alive with the aid of herb-roots and tree-barks in bad years. So, "one bowl of rice" was an earnest wish to Koreans in those days, but even the Korea's independence in 1945 could not bring rice to them. Through the Korean War (1950-1953) the food situation became extremely worse. In the post-war period, the daily food consumption per person was $600 \mathrm{~g}$ in the 1950s, less than $1 / 2$ the average food intake of Koreans today [9]. Even till the 1970s, most peasant families had to go through what was known as the "barley hill" or "spring poverty", the period from when the rice they produced the previous year ran out and the time when the spring harvest of barley was ready (Fig. 9). In such situation, rice self-sufficiency was a nation's long-cherished wish: Give me rice or give me death?

\section{The Second Stage (1960s): Encouraging}

\footnotetext{
7"Han" is a concept in Korean culture attributed as a unique Korean cultural trait which has resulted from Korea's frequent exposure to invasions by overwhelming foreign powers.
}

\section{the Use of Flour \& Rice with Mixed Grains for Food}

During this second stage in 1960s, bad harvests caused by severe draughts were so frequent that Korean government did not only attempt to build many dams with farm land arrangements, but also push forward state mobilization policies to intensify food production while controlling rice consumption among the public. Accordingly, the government encouraged people to eat more flour-based food and boiled barley (or rice with other mixed grains) to combat rice shortages. Especially, flour-based foods were so popular, with large-scale imports of American wheat flour (surplus produce) in 1963. Suddenly, traditional rice-based diets became a target of criticism. In the name of people's dietary life improvement, the cult of flour foods started to cover the whole country! Even, the "Flour food day" was established by law, according to which restaurants should serve only flour-based foods on every Wednesday and Saturday (Fig. 10). Many pro-flour food campaigns were held by active women's organizations all over the country. Thus, flour consumption, such as noodles, ramen, breads and cookies, explosively increased. Flour became the lord on the table. In those days, mass-medias preached that wheat flour was more nutritious and healthier than rice while castigating rice-eaters for being "unpatriotic." Riding on the waves of modernization, a kind of "cultural toadyism" based on pseudo-dietetics became the mainstream in Korean society. For example, eating rice can make you dump. Flour is richer in calcium and protein than rice, so flour makes you taller and healthier, etc. As a result, it worked so well to Koreans. The driving force in the success of the nation-wide campaign for flour foods was nothing but a strong longing for Western-styled life. In particular, flour-food consumption was considered as a symbol of Westernization among Korean middle-class families. However, this vigorous flour consumption 


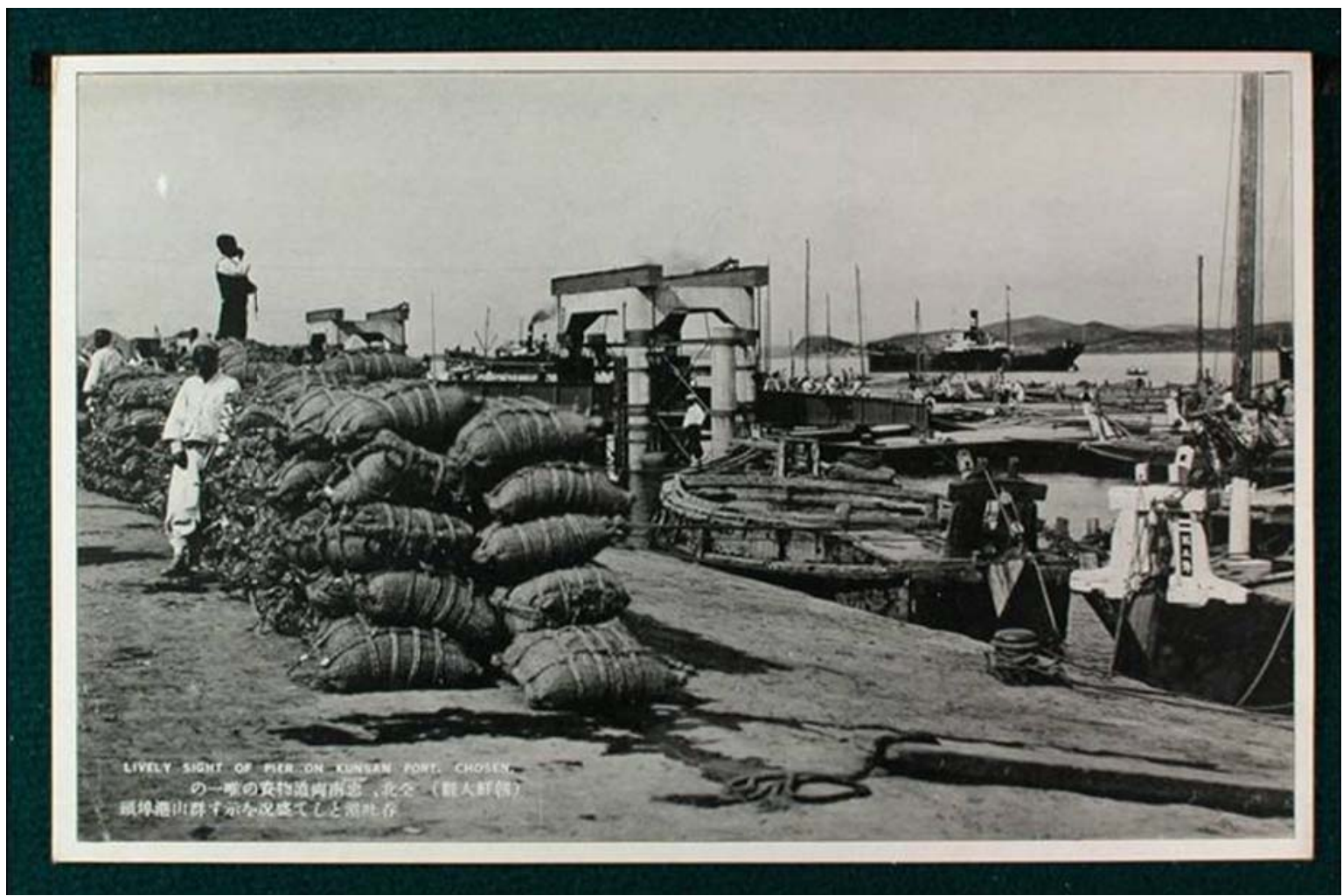

Fig. 8 A mountainous heap of rice bags in the harbor of Gunsan, Korea in 1890s.

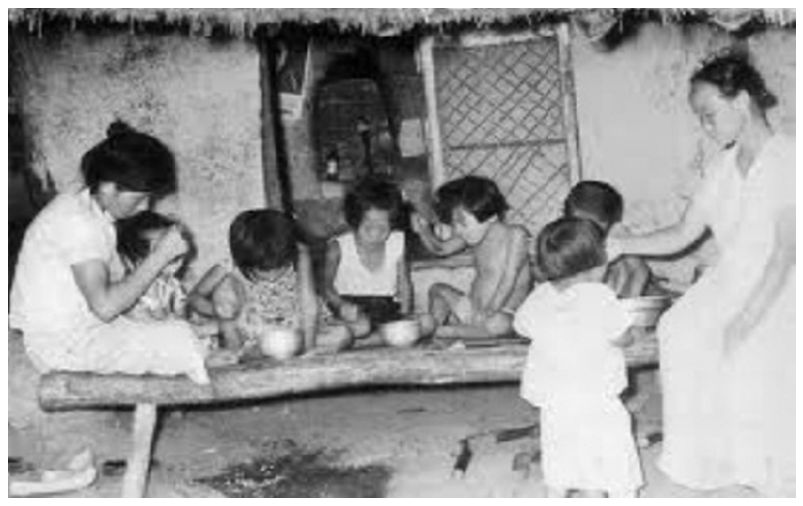

Fig. 9 Season of spring poverty.

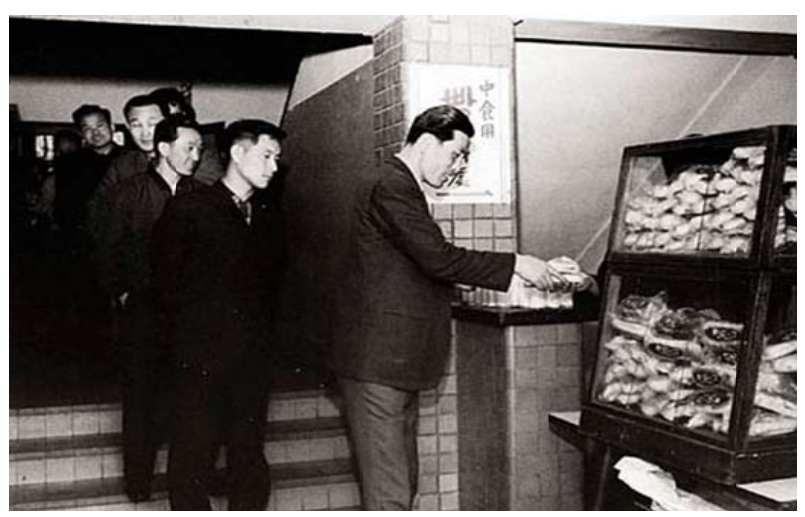

Fig. 10 National campaign for encouraging the use of flour for food.

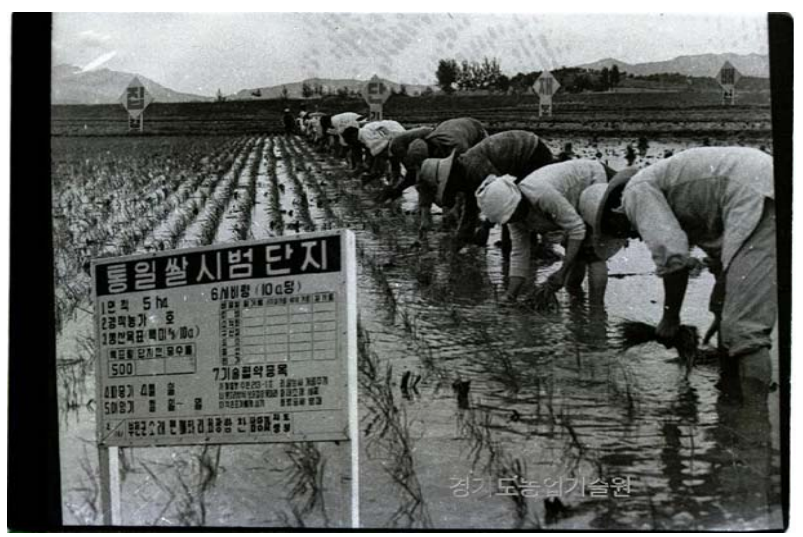

Fig. 11 Unification rice growth model.

movement progressively stepped back with the development of new high-yielding "unification rice (tongil rice in Korean)" in 1977 (Fig. 11). From 3, 040, 000 in 1960 into 3,940,000 tons of rice in 1970, its high-yielding ability (5.13 ton/hectare) paved the way for rice self-sufficiency [10].

\section{The Third Stage (1970s): Rice Self-sufficiency}

With the rapid dissemination of unification rice, 
rice production increased while rice imports decreased. In 1976, Korea finally succeeded in being self-sufficient in rice. Rice yield ability $(\mathrm{kg} / 10 \mathrm{a})$ climbed from 304 in 1960s to $494 \mathrm{~kg}$ in $1977(+62 \%)$ [11]. In 1978, rice production climbed to $4,000,000$ rice bags, laying the cornerstone of so-called "Green Revolution." Under the former dictator president Park's regime (1961-1979), rice farming was highly regulated to achieve the national goal of rice self-sufficiency. Korean leftists used to criticize it as an empty rhetoric of low-priced grain policy to provide cheap labor forces to industrial field.

Increasing crop yields significantly through the variety improvement, the use of intensive agriculture, artificial fertilizers and pesticides, etc. remained common in underdeveloped countries, as well as in Korea in 1960s. In the cold-war period, the US was rightly keen to keep South-East Asian and African countries from going communist. Upon the insistence of American economists, including Walt Whitman Rostow (1916-2003), newly independent nations could not only secure basic resources for industrialization, but also stop farmers from being infected with communism, only if absolute poverty problem would be solved by raising agricultural productivity. The Green Revolution Americans conceived in those days was, so to speak, a corrective measure to prevent the spread of Red Revolution.

As a fair trader, Korean government began to purchase high-yielding, but "less tasty" unification rice (Fig. 12). Since then, rice has been divided into two categories: government-controlled rice (jongbu-mi) and ordinary rice (ilban-mi), generic term for non-unification rice. The government rice, often called "president rice" was stigmatized as the rice for the poor. There was so an equation of government rice

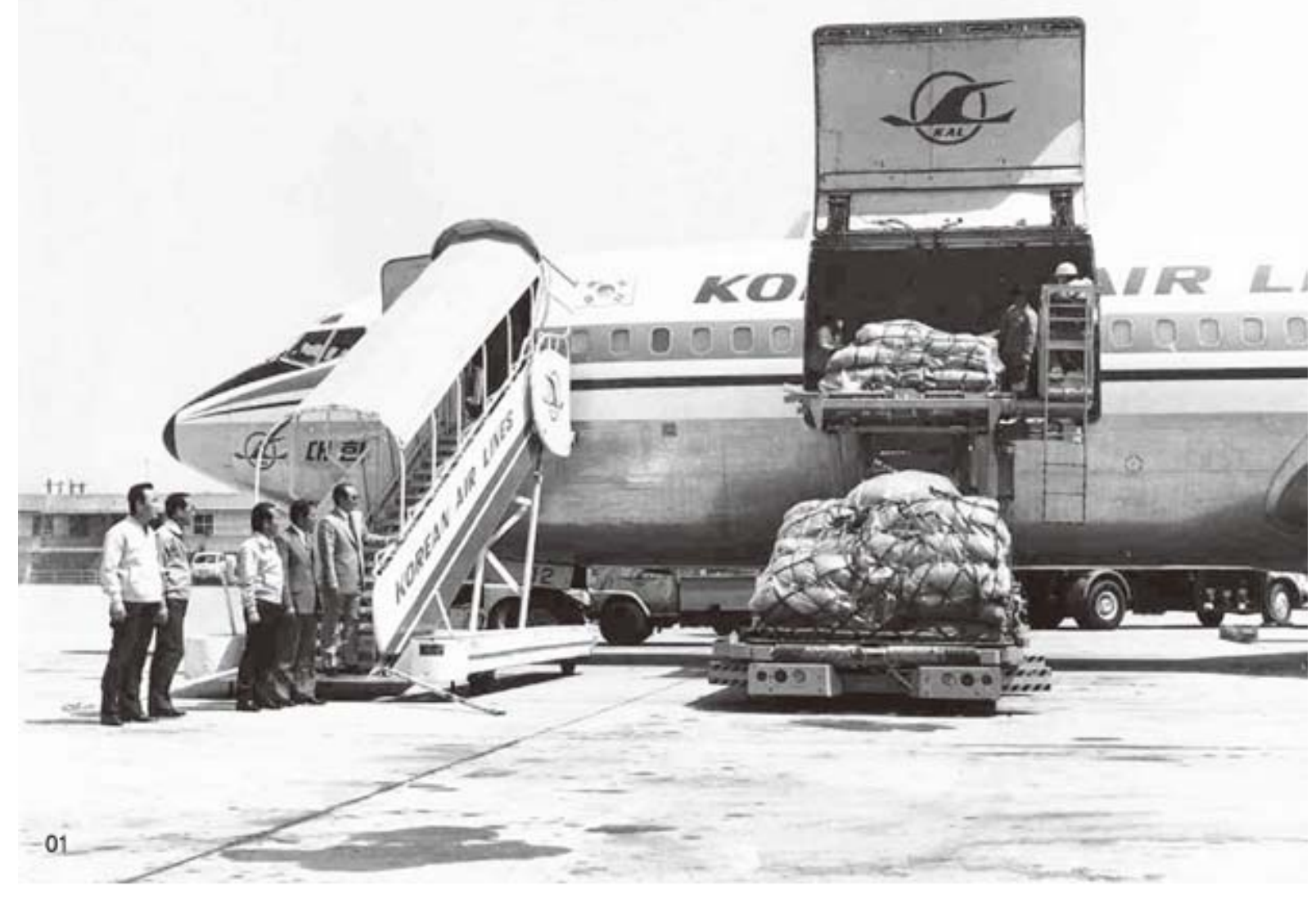

01. 동일벼 품종을 필리핀에서 공수하는 모습 (c)농촌진흥청

Fig. 12 Air transportation of rice variety from Philippine. 
with bad rice. Even though middle and upper class families ate more expensive ordinary rice, poor and rich alike used to buy rice in small retail store called "ssajon" in Korean, before the brandization of rice in 1990s (Fig. 13). From the 1970s to the early 1980s, the terms "jongbu-mi" and "ilban-mi" which already have become "obsolete" were used in very high frequency, because of the importance of rice as the staple food (Table 2).

\section{The Fourth Stage (1980s): Change of Rice Culture}

As Korea has evolved into manufacturing-oriented industrial society, the importance of agriculture has steadily decreased. Rice was no longer the symbol of wealth by losing its socio-economic and political importance. In the past, acquiring farmland was a way of wealth accumulation, but it has considerably dropped in exchange value. Rural areas were considered as "backward", in comparison to urban areas. Rice was still an integral part of Korean dietary culture, but creating national wealth through agricultural production has abated with rice self-sufficiency in 1970s. In accordance with the rapid economic growth and industrialization, there were several new phenomena, such as value shifts, gentrification of food, fast-foodization, and food service industry boom, etc. With the increase in income, Koreans tended to show an over-consumption of food and high meat intake. Along with the success of "White Revolution of Agriculture" which enabled a year-round production and distribution by the expansion of greenhouse cultivation, Korean vegetable consumption also increased. Thus, Korean rice consumption relatively declined.

In retrospect, rice was a symbol of inter-Korean conflicts, being on the victor's side in the ideological competition between North and South Korea, depended on how much and how often to feed people with rice. InSeptember, 1984, whenthe damage from

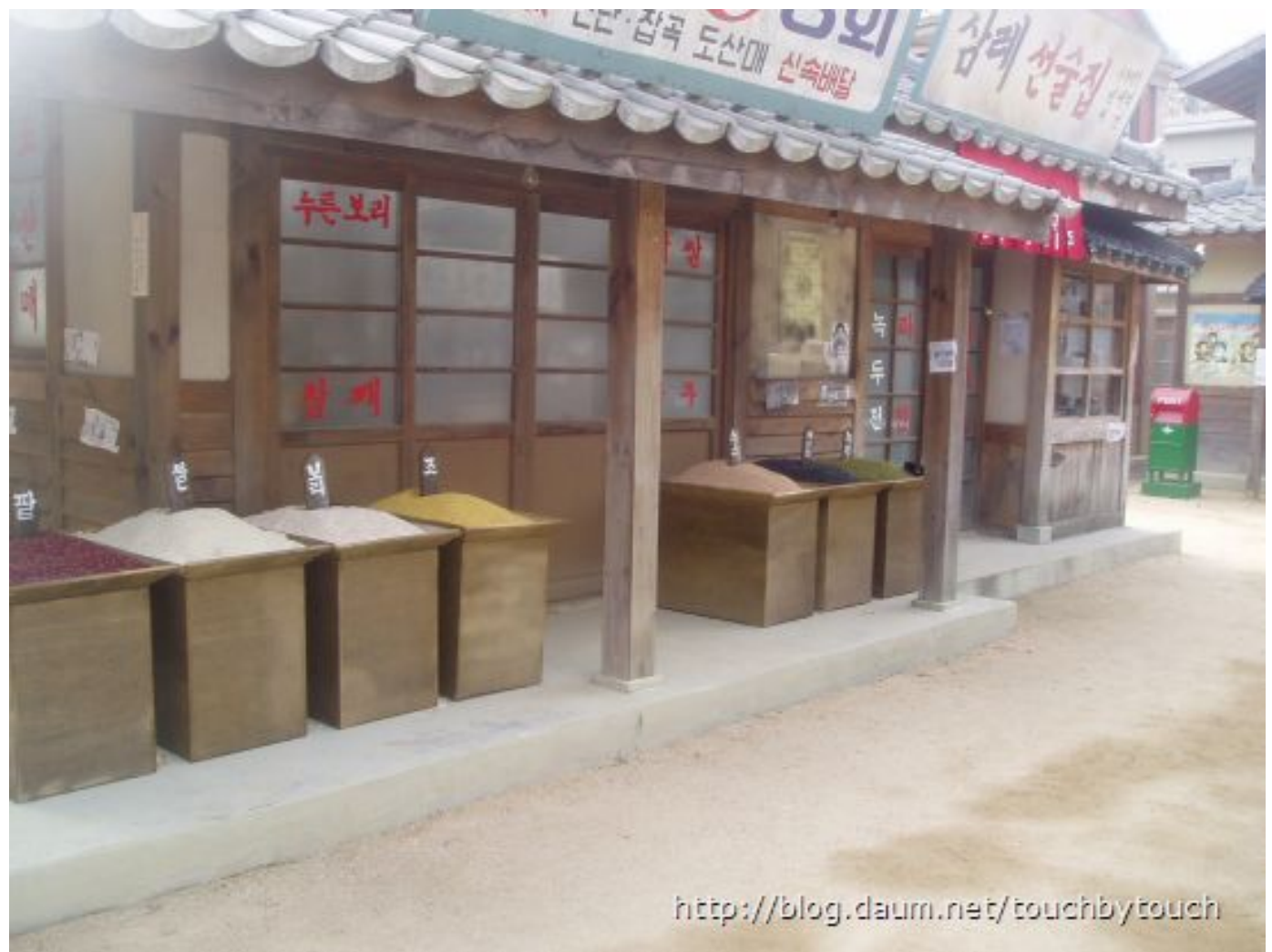

Fig. 13 Rice retail store "ssajon". 
Table 2 Frequency in use of the terms “jongbu-mi” and “ilban-mi” by year [12].

$$
200
$$

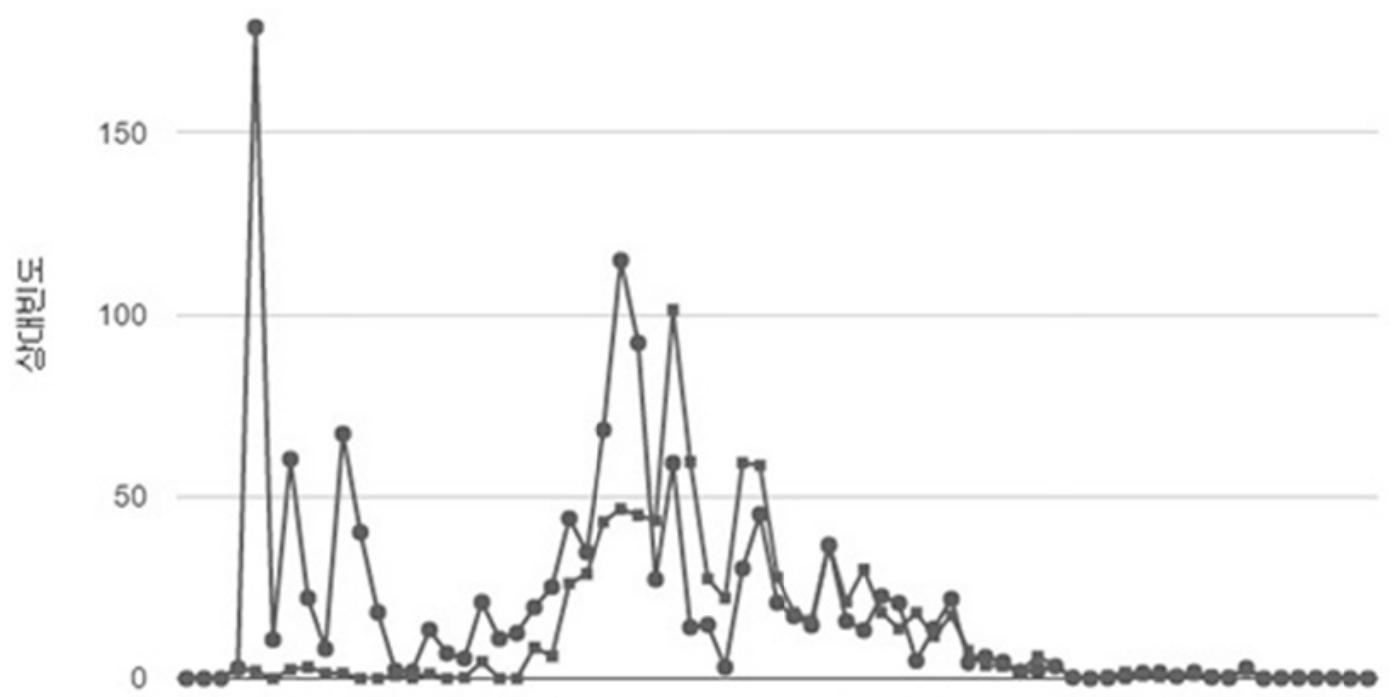

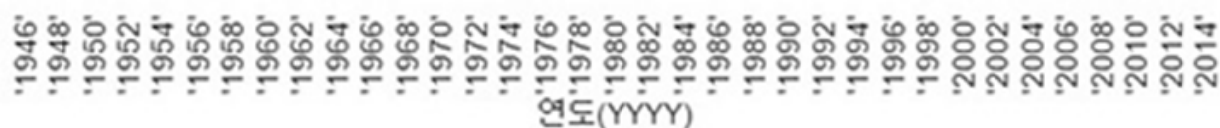

$$
\rightarrow \mathrm{N} / \text { 정부미 } \rightarrow \mathrm{N} / \text { 일반미 }
$$

Jongbu-mi: --•--Ilban-mi: --п--.

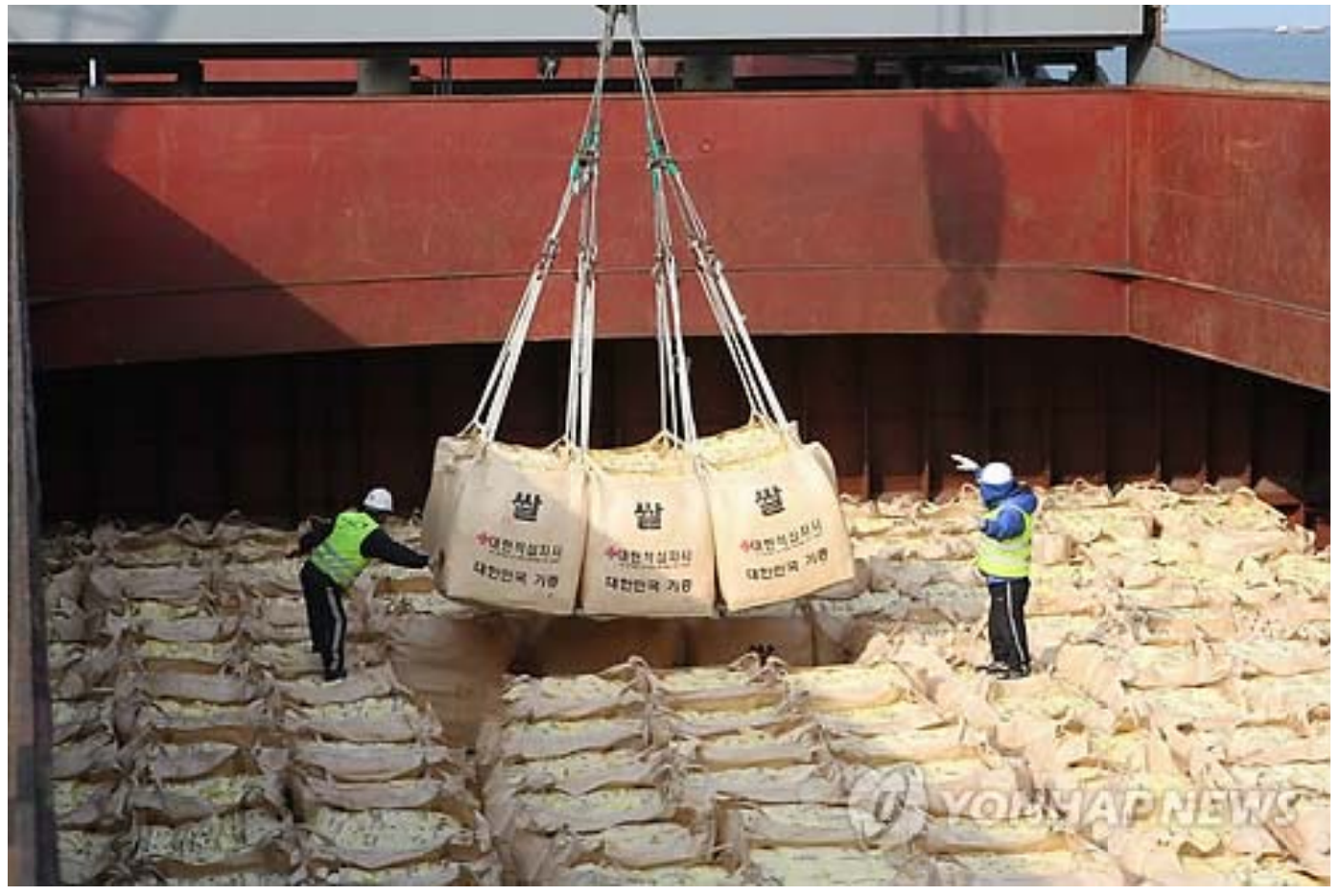

Fig. 14 South Korea's rice aid to North Korea. 
the flood was disastrous in South Korea, North Korea unexpectedly proposed to send rice to South Korea. The North's newspaper spotlighted it as the greatest activity in the 40-year division history, emphasizing the superiority of North Korean communist regime. However, North's rice was of very poor quality. To North Korea it was a "relief" to help starving and ragged South Korean compatriots, but to South Korea it was a memory-stirring "souvenir" which reminded some older people of the seasons of spring poverty in the past.

Currently, there is a surplus of rice in South Korea, while North Korea is suffering from a food shortage. Due to Pyongyang's launch of missiles, South Korea's humanitarian rice aids to North temporarily remain suspended. In the future, rice will be a "link" to build a bridge over a river of disharmony between two Koreas. In a 1999 South Korean action film called "Shiri", a North Korean leader in his last battle delivered the following remarks on-screen: "you guys grew up on rotten cheese, coke and hamburger. So, you never really know the agony of your North Korean compatriots or the meaning of our reunification (under communism)." Rice is a keyword to social solidarity between two different Koreas, if rice aid begins again (Fig. 14). According to a civil campaigner, rice is also a keyword of Korean social solidarity against the US-led globalization which gallops without a break.

\section{The Fifth Stage (since 1990s): Stabilization/Stagnation of Rice Culture}

Thanks to the development of various rice varieties by use, such as scented rice, colored rice, and rice for brewing \& frying, and the "brandization" of rice, consumer options have broadened (Fig. 15). However, the Western-oriented eating habits among adolescents have continually reduced rice consumption since the 1980s. Rice has become a surplus of food. Korean food self-sufficiency was very low in general, but rice attained almost $100 \%$ of self-sufficiency from 2000 to 2006, as represented in Table 3 below.

According to the previous "dilly-dally" government policies, only unpatriotic and less patriotic people seemed to eat (little nutritional, but expensive) rice in oil-poor country. At that time, rice was considered as lumps of carbohydrate or very harmful to female diet and beauty treatment by wrong

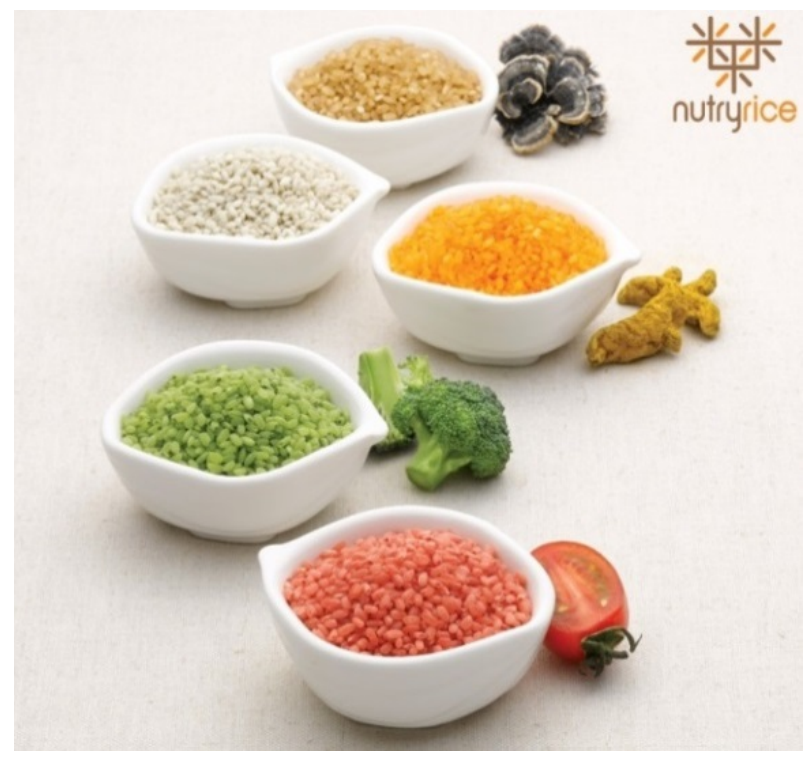

Fig. 15 Colored rice.

Table 3 Trends of Korean grain and stock-raising self-sufficiency rate (unit: \%).

\begin{tabular}{llllllll}
\hline Period & 2000 & 2001 & 2002 & 2003 & 2004 & 2005 & 2006 \\
\hline Grain (including feed grain) & 29.7 & 31.1 & 30.4 & 27.8 & 26.9 & 29.4 & 28.0 \\
Grain (excluding feed grain) & 55.6 & 56.8 & 58.3 & 53.3 & 50.2 & 54.0 & 53.6 \\
Rice & 102.9 & 102.7 & 107.0 & 97.4 & 96.5 & 102.0 & 98.9 \\
Meat & 78.8 & 75.4 & 76.6 & 70.8 & 79.3 & 76.0 & 70.6 \\
Beef & 52.8 & 42.3 & 36.6 & 36.3 & 44.2 & 48.1 & 47.9 \\
\hline
\end{tabular}

Source: Food, Agriculture, Forestry and Fisheries Committee. 
food faddism ${ }^{8}$. Nowadays, the government is reversely engaging in promoting rice as a perfect food, but Koreans are already accustomed to eating other various flour-based foods. In 2014, per capita daily rice consumption reached an all-time low (178.2 g) showing a clear decreasing trend for more than 30 consecutive years ${ }^{9}$ [13]. Since records began in 1963, it was nothing more than $47.7 \%$ of $373.7 \mathrm{~g}$ in 1970 , year of highest rice consumption. If we put the case that one rice bowl is $100 \mathrm{~g}$, it means that Koreans eat less than two bowls a day. Since 2010, per capita per day rice consumption has been below $200 \mathrm{~g}$, while mixed grains $(25 \%)$, beans $(19 \%)$, potato and sweet potato $(3.7 \%)$ have showed an increasing trend owing to the popularity of "wellness" trends. On the other hand, the westernized Korean dietary life has led to obesity and various adult diseases.

After 1980s, rice overproduced, but due to the rice protection policy it was forbidden to be exported to foreign countries. Since 2007, rice has been exported, but it counts only hundreds of tons per year. When North and South Korean relations were good, from 2000 to $2005,400,000$ tons of rice aid was sent to the North Korea every year, which decreased the rice in stock. After the deadlock of inter-Korean relations, the rice stock was piled up with the decrease in domestic rice consumption. Thus, it was proposed to send rice to Africa, but rejected due to expensive long-distance transport costs. Moreover, Africa is not only a rice cultural zone, but African rice is also different from Japonica ones that are usually consumed in East Asia.

The "(re-) sacralization of Korean rice"-systematically formed around the Uruguay Round which made all countries on the globe trade with the US was also adding to the problem. At that time, the government attempted to solve the problem of rice surplus by anachronically returning the already-Westernized Korean dietary pattern to

\footnotetext{
8 Food Faddism is a dietary practice based upon an exaggerated belief in the effects of food on health and disease.

${ }^{9}$ Per capita rice consumption has decreased since 1980.
}

traditional one where full big rice bowl was the object of envy (?!), but failed by disregarding the reality. Koreans' obsession with rice and its sacralization prevented the rational economic policies. The Ministry of Agriculture and Forestry presented a plan of selling long stored rice for use as animal feed, but withdrew it facing a serious backlash: "how to feed animals with so precious rice?" Eventually, this surplus rice held in state reserves came into the market to lower the price of rice in 2011 when the rice crop failed. But local farmers kicked at the government's measure of bringing rice prices down. Rice cookies and ramen by using lower quality rice were introduced into market, but went to the wall because they hardly got a favorable evaluation by the public: rice from enfant cheri to public nuisance.

\section{A Government Rice's Diary:}

“Hello! My name is Nampyong-mi (rice). I'm a second-class government rice. I live now in state reserve. I'm five years old. Five in rice life-cycle is the retirement age. I'm one of the senior members. Senior is not good, this means being in a state of total neglect or not being selected by humans. There are the lucky ones that were already sold out to restaurants, school food services, troops, prisons, and social service agencies, wearing a name tag "newly harvested rice." Some 2 or 3 year-old rice was sent to North Korea to save starving North Korean compatriots. The destiny of 5-year old seniors like me is to finish their life as becoming diluted sojus (Korean distilled spirits) with sweet potato and tapioca. Some of them were also sold out as gochujang (hot pepper paste) ingredients, rice biscuits, makgeolli (rice wine) and rice powder, or exported into Africa as steamed rice.

I used to be one of the glorious leaders in our rice field. I was sold at 5,000 won per sack as government rice. So, my master was greatly pleased with a sales statement he received after selling me to the government. Now, I just cost at 280 won per $\mathrm{kg}$ 
(falling down to $20 \% 5$ years ago). I and my colleagues had no sunshine for 5 years in state reserve.

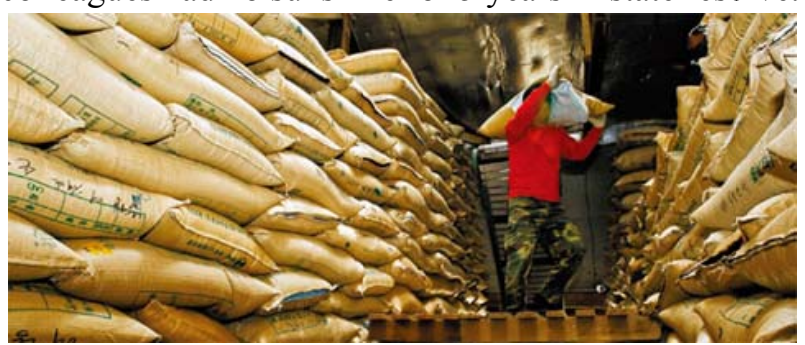

Fig. 16 Government rice in state reserve.

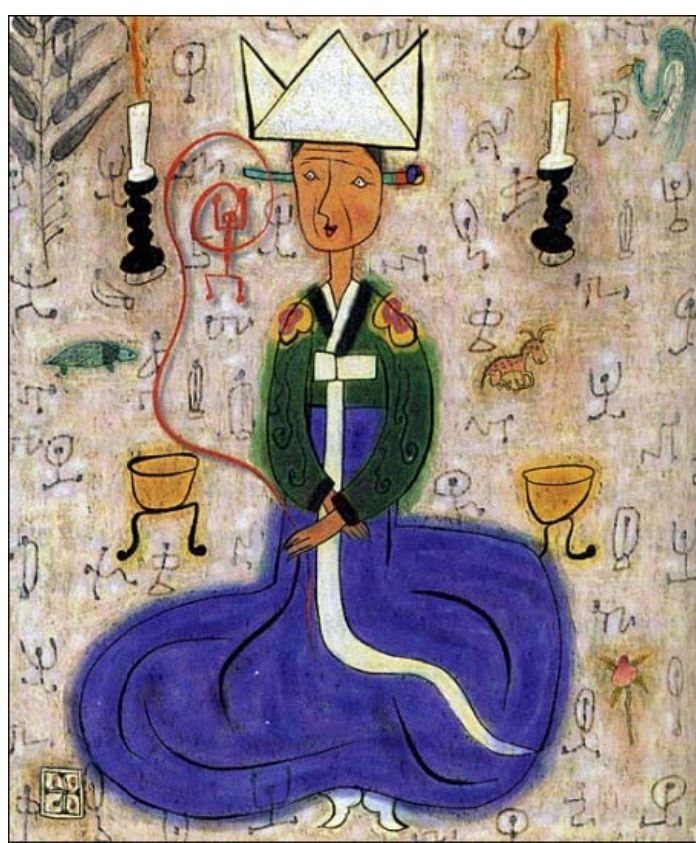

Fig. 17 Grandma Samsin (the goddess of birth) painted by Korean visual designer Jun Gap-bae (1951-).

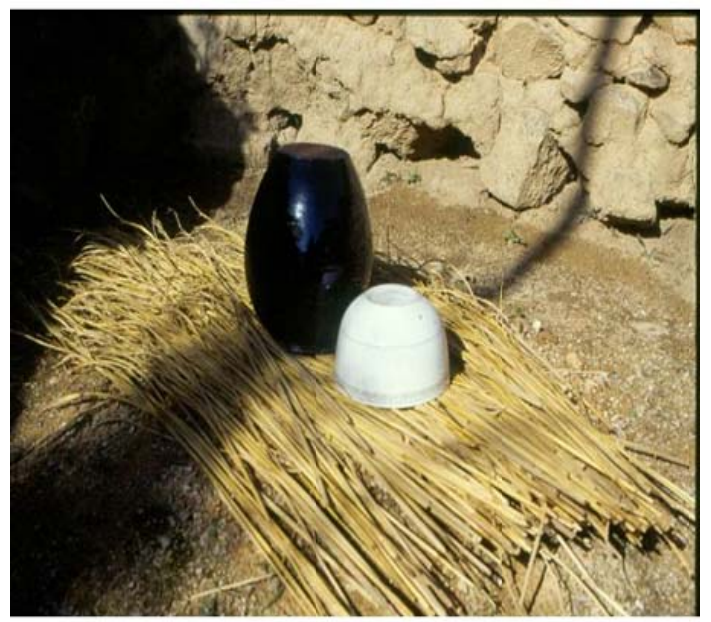

Fig. 18 Rice straw praying for a safe and easy delivery.

Before the end of this year, I should leave here to be carried by truck into a rice wine factory as stale rice.
I'd like to ask who is responsible for compromising me in such a pitiable condition?" [14] (Fig. 16).

\section{Conclusion: Industrialization of Rice}

Rice is a "soul food" for Japanese and Chinese in similar rice culture zone, as well as for Koreans. For reference, rice was adored as a water god of the rice paddy (Ta-no-kami) in Japanese ancient culture [15]. Even today rice becomes a link between god and humanity in Japanese Archipelago [16]. As opposed to their economy-centered way of thinking, Japanese demonstrated against opening the market to foreign rice imports, when the rice import issue became public. Of course, their level of opposition to market-opening pressure was smaller or less strong than Korean one.

Since the beginning of rice farming, rice has controlled the entire lives of Koreans from the birth to the grave. In old days, Koreans used to set the table for praying to Grandma Samsin (the goddess of birth) with rice, seaweed and fresh drawn water, before the baby's birth (Fig. 17). In the backyard, rice straw was also spread as hoping for a safe and easy delivery (Fig. 18). After giving birth, mother usually ate rice and seaweed soup called "miyokguk." 10 A rice bowl and a set of spoon \& chopsticks were widely given to a child as an event in celebration of the first birthday. The first baby food was thin rice gruel. On the other hand, a traditional Korean custom used to put one spoon of raw rice into the mouth of the deceased at the burial, as the last earthly food during the journey to the underworld.

Rice was the measure of all things for agricultural people who live on rice as a staple food. Thus, human personality or economic strength of households was often measured by rice, as the proverb says "charity begins in the jar of rice." It means that one has to be full before feeding others.

Rice is called " $m i$ (米)" in Chinese. This Chinese character 米 is divided into 3 parts: 八十八 (88).

${ }^{10}$ The miyok-kuk is a Korean soup made from the seaweed known as "miyok" in Korean. It comprises two words: miyok, the Korean word for wakame; and guk, meaning "soup". 
This means that rice requires a great deal of care (more than 88 times). Otherwise, 88 persons' labor is, at least, needed to make a grain of rice in one accord. Kwon Sam-yoon, author of the Korean book Bread Makes a Road, While Rice Makes a Village (2007), found the starting point which has produced the great differences between eastern and western cultures since the dawn of civilization, in "rice and bread cultures." Thus, the boundary between the East and the West did not seem to be based on geographical conditions, but on what you ate and you are eating now as a staple food. Fernand Braudel also pointed out the three great cereal crops - wheat, rice and maize - that feed most of the world people, as "foods of civilization," in his chef-d'oeuvre Civilisation matérielle, économie et capitalism. According to Kwon, closed, labor-intensive and village community-centered societies are formed in east, whereas opened, efficient, labor-dispersive and road-centered societies are settled in west. Bread is a food suitable for building a road while moving, but rice is a food for making a rural village by gathering and eating together. So, bread and rice are not only a byword for generic food, but a cultural starting point in two different civilizations.

In this regard, rice is a basis of Korean national identity, but rice today is not properly treated by internal and external troubles: reduction in rice consumption and market-opening pressure. Most people show indifferent attitudes and outlooks on the rice problem as lookers-on. Rice is still a national soul or a lifeline for farmers who grow local rice, ${ }^{11}$ but for many urban dwellers-including proponents of open-door policy_rice is just one of the industrial products, such as mobile phones and cars.

It is often said that food is the most resistant to the change in the necessities of life (food, clothing and shelter). Nonetheless, the meaning of rice was

\footnotetext{
${ }^{11}$ When South Korea agreed to open its rice market in 1994 under the Uruguay Round multilateral trade talks, then-President Kim Young-sam (1927-2015) had to apologize to the people for revoking his campaign promise that, if elected, he would stake his presidency on protecting the local rice market from imports.
}

drastically changed two times in the model of developmental state aiming at "remodeling consciousness structure" by rooting out tradition: firstly by rapid industrialization with the decrease of agricultural importance; and secondly by import globalization. For this reason, some nutritionists told that rice is a staple food "in our mind". Vis-à-vis the opening of the world market, Korean government, government-related organizations, farmers' associations and farmers themselves desperately endeavored to survive Korean local rice, on mass-political level. The government's official position on the matter was clear. The opening of rice market is a collapse of Korean agriculture and rice import is nothing but an overseas dependency. Some attempt to cope with the foreign powers represented by the WTO by belatedly reviving the traditional image of rice based on "nationalistic" or "socially solidaristic" paradigm. With recent increasing concern for health, rice becomes a symbol of nourishing food or health food for others. Or with the environmental concerns, (organic) rice becomes a byword for environment-friendly agricultural product. Thus, rice is still the medium through which Koreans express their knowledge and attitude about basic life.

The reasons for the dramatic decline in rice intake are as follows. Young people prefer western-style convenience foods to rice-based traditional ones. ${ }^{12}$ The traditional extended family system is breaking up in favor of the nuclear family with working mother. After the law for school feeding in 1981, young students often skip breakfast or eat bread instead of rice in the morning. Under the financial pressure, poor quality rice is usually provided in school lunch, so many pupils avoid eating rice. In particular, 4-7 years old preschool children eat hamburger, toast and noodles, as lunch or snack. Eating habits are generally acquired during the early years of childhood. For this reason it is very important that healthy eating is

\footnotetext{
${ }^{12}$ Rice intake is higher in low and high-incomers and unskilled/skilled workers than middle-incomers and specialized/office workers.
} 
encouraged from an early age. Thus, maintaining rice-centered Korean diet cannot only increase rice consumption on the dimension of food security, but also enhance the health of young people who are exposed to fast food logos such as McDonald's and KFC. According to the statistical data published by National Health Insurance Corporation (1992-2000), the number of overweight Koreans especially in their teens and 20 s increased from $10 \%$ into $32 \%$ for 8 years [17]. Such a rapid increase in the rate of obesity was mainly due to the structural change of eating habits among younger generation who are very fond of fast foods.

A long-term effort to no longer reduce rice consumption is a task with sustained attention and awareness. Appealing to Koreans' patriotism as the authoritarian government did in the past is out of use, so it is necessary to devise more technical solutions, closely related to the "industrialization of rice." First, the processerization of rice food and the development of rice fast-food chains are needed. The high palatability and high frequency of western-convenience food among youth and adults are corroborated by the total sales of Korean food service $\&$ dining-out industry (fifteen trillion won). Korean critic and novelist Lee O-young wrote in his representative essay "Bread and Rice" anybody can eat bread while walking on the road, but nobody may eat rice strolling in the street, except a beggar. However modernized one may be, steamed rice shops will not be as many as bakeries! It's not possible for him to imagine that ready-made rice is sold out in the shop. But if there are processed rice chains, the number of people buying and using them will increase. In the case of Japan, ${ }^{13}[18]$ eating donburi, natto rice, onigiri (Japanese rice ball), cooked and frozen rice at home and in restaurants near subway station or

\footnotetext{
${ }^{13}$ In Japan, rice processing industry has been developed to solve the rice surplus issue since around 1969. Thus, $13 \%-15 \%$ of total rice production is used for processing rice (steamed rice, rice snack, rice wine, rice condiment, rice drink, rice noodle and rice cake, etc.)..
}

company, before going to work is becoming too much of a norm. So, it requires an effort to make more technical and more healthful rice fast-foodization and chainization.

Second, it should provide high-quality functional rice to consumers looking for more tasty rice. The reason why the unification rice only focused on "high-yielding" has all but disappeared in the market was in a failure to catch up gentrified consumer' $s$ taste. As the final outcome, it depends on how to apply healthy and eco-friendly processing techniques to the rice management system: polishing, processing, storage and distribution in the brandization of good-quality rice.

\section{References}

[1] Choi, N. K. 2014. "Rice Addiction in Chosun Period." http://www.seehint.com/hint.asp?no=13628 (in Korean)

[2] Korean Food Foundation. 2014. Korean Food Culture Series 3: Modern Korean Cuisine. Seoul: Hollym Corporation: 154. (in Korean)

[3] Jung, S. H., and Jung, K. J. 2014. Korean Food, Clothing and Housing Culture. Seoul: Samin Publishing Co.: 122-15. (in Korean)

[4] Tawney, R. H. 1966. Land and Labor in China. Boston: Beacon Press, 77.

[5] Woo, D. H. 2005. "The Introduction of New Rice Technology and Its Impact on Rural Structure in Colonial Korea." Society and History 68: 234. (in Korean).

[6] Joo, Y. H., et al., 2013. One Bowl of Rice Which Includes World. Seoul: Gildam Academy: 37. (in Korean)

[7] Kim, M. S. 2012. "Origin and Background on Popularization of Rice-Based Diet in Japan." Korean Journal of Agricultural History 11 (2): 144-5. (in Korean)

[8] Korean Wikipedia. "Japanese Colonial Rice-Increasing Policy." (in Korean)

[9] Lee, C. H. 2013. Studies on the Measures to Enhance Food Self-sufficiency. KAST Research Report, KRR 91: 3. (in Korean)

[10] Kim, Y. K. 2010. "Rice." The Technology and Science 496: 19. (in Korean)

[11] Choi, I. S., et al., 2012. "Evolution of Rice." RDA Interrobang 66: 16. (in Korean).

[12] Choi, J. W., et al., 2015."Chronological Changes Viewed by Popular Keywords." New Life of Korean Language 25 (4): 61. (in Korean)

[13] Lee, S. W. 2015. "The Lowest Rice Consumption Per Capita." Yonhap News, January 27 (newspaper) (in Korean) 
[14] Choi, J. H. 2010. "Five is the Retirement Age in the Life of Government Rice.” Joong Ang Sunday, November 11 (newspaper) (in Korean)

[15] Kim, M. S. 2012. "The Origin of the Popularization of Japanese Rice Consumption and Its Background." Korean Journal of Agricultural History 11 (2): 135. (in Korean)

[16] Kim, M. S. 2012. "The Origin of the Popularization of
Japanese Rice Consumption and Its Background.” Korean Journal of Agricultural History 11 (2): 135.

[17] Cho, M. S. 2010. "Rice and Healthy Diet." The Journal of East Asian Society of Dietary Life: 23. (in Korean)

[18] Lee, H. W. 2010. "The Processing Industries of Rice and Industrialization of Cooked Rice in Korea." Bulletin of Food Technology 23 (4): 457. (in Korean) 